NATURWISSENSCHAFT UND PHILOSOPHIE 



\title{
NATURWISSENSCHAFT \\ UND \\ PHILOSOPHIE
}

\author{
BEITRAGE ZUM INTERNATIONALEN SYMPOSIUM UBER \\ NATURWISSENSCHAFT UND PHILOSOPHIE \\ ANLÄSSLICH DER 550-JAHR-FEIER \\ DER KARL-MARX-UNIVERSITÄT LEIPZIG
}

\author{
Herausgegeben von \\ GERHARD HARIG \\ und \\ JOSEF SCHLEIFSTEIN
}

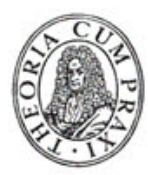

AKA DEMIE-VERLAG • BERLIN • 1960 
Wissenschaftlicher Redakteur: Rudolf Rochhausen

Brachienen im Akademie-Veriag GmbH, Berlin W 1, Leipziger StraBe 3-4 Copyright 1960 by Akademie-Verlag GmbH, Berlin Alle Rechte vorbebalten

Lizenz-Nr. 202 - 100/189/60

Satz, Druck und Bindung: IV/2/14 - VEB Werkdruck Grăfenhainichen - 1366 Bestellnummer 5399

Printed in Germany

ES 3 B 4 